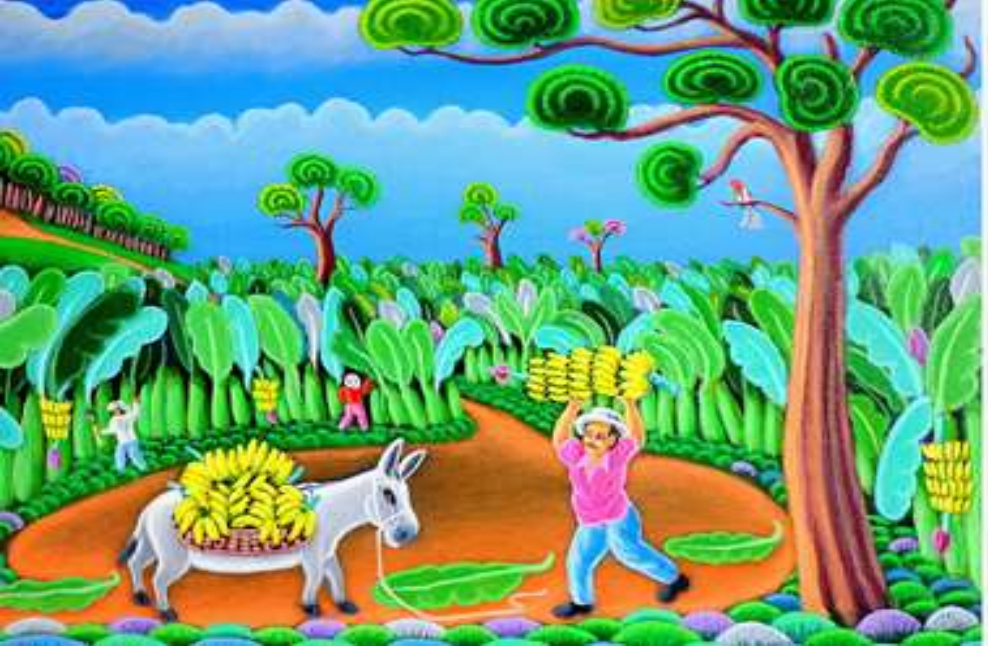

\title{
AS CORES DA VIDA: ESTRATÉGIAS BIOPOLÍTICAS NAS CAMPANHAS SETEMBRO AMARELO, OUTUBRO ROSA E NOVEMBRO AZUL
}

\section{THE COLORS OF LIFE: BIOPOLITICAL STRATEGIES IN THE YELLOW SEPTEMBER, PINK OCTOBER AND BLUE NOVEMBER CAMPAIGNS}

\author{
Jaqueline de Jesus BEZERRA \\ Universidade do Estado do Rio Grande do Norte, Brasil
}

Francisco Vieira da SILVA Universidade do Estado do Rio Grande do Norte, Brasil

RESUMO | INDEXAÇÃO | TEXTO | REFERÊNCIAS | CITAR ESTE ARTIGO | O AUTOR RECEBIDO EM 02/05/2019 • APROVADO EM 21/11/2019

\section{Resumo}

O presente trabalho apresenta uma análise de estratégias biopolíticas em campanhas do Setembro Amarelo, Outubro Rosa e Novembro Azul. Para compor o corpus, selecionamos três materialidades discursivas, uma campanha do Setembro Amarelo, outra do Outubro Rosa e outra do Novembro Azul, respectivamente. Esta pesquisa é descritivo-interpretativa, de abordagem qualitativa, fundamentada, especialmente, em Foucault (2005), no que se refere às noções de biopoder e biopolítica. A partir da análise, foi possível perceber que as estratégias biopolíticas das campanhas em questão se realizam por meio de um discurso de prevenção de 
doenças, a fim de que a saúde seja assegurada e, consequentemente, a vida seja preservada e valorizada.

\section{Abstract}

The present work presents an analysis of biopolitical strategies in the campaigns of Yellow September, Pink October and Blue November. To compose the corpus, we selected three discursive materialities, one Yellow September campaign, one October Pink campaign and other Blue November campaign, respectively. This research is descriptive-interpretative, with a qualitative approach, based especially on Foucault (2005), regarding the notions of biopower and biopolitics. From the analysis, it was possible to perceive that the biopolitical strategies of the campaigns in question are realized through a discourse of disease prevention, so that health is ensured and, consequently, life is preserved and valued.

\section{Entradas para indexação}

PALAVRAS-CHAVE: Biopoder. Biopolítica. Discurso. Setembro Amarelo. Outubro Rosa. Novembro Azul. Biopoder. Biopolítica. Discurso. Setembro Amarelo. Outubro Rosa. Novembro Azul.

KEYWORDS: Biopower. Biopolitics. Discourse. September Yellow. Pink October. Blue november.

\section{Texto integral}

Considerando-se que a biopolítica atua na preservação da vida e na prevenção de doenças (FOUCAULT, 2005), este trabalho apresenta como objetivo analisar estratégias biopolíticas em campanhas do Setembro Amarelo, do Outubro Rosa e do Novembro Azul, bem como objetiva, especificamente, discutir sobre o biopoder, a biopolítica e seus alvos de controle e atuação, sobretudo à luz dos pressupostos de Foucault (2005), que traz à tona as mudanças na forma de organização do poder, apresentando-nos o biopoder.

A primeira campanha que compõe o corpus, do Setembro Amarelo ${ }^{1}$, foi criada pelo Núcleo de Inclusão e Acessibilidade da Uniasselvi, instituição privada de ensino superior do estado de Santa Catarina. A segunda campanha, do Outubro $\mathrm{Rosa}^{2}$, é de iniciativa do Sistema de Gerenciamento de Programas do Ministério da Saúde. A terceira e última campanha, do Novembro Azul ${ }^{3}$, foi criada pela Eco Desenvolvimento, plataforma online de comunicação especializada em sustentabilidade e pela Fundação José Silveira, instituição privada.

Escolhemos as campanhas do Setembro Amarelo, do Outubro Rosa e do Novembro Azul por serem as mais conhecidas em relação à discussão de temas em meses específicos. Para cada mês do ano há uma campanha, no entanto, as mais conhecidas são as dos meses de setembro, outubro e novembro, que buscam, respectivamente, a prevenção do suicídio, do câncer de mama e do câncer de próstata. 
A campanha Setembro Amarelo teve início em 2015 com o objetivo de conscientizar a população para a prevenção do suicídio e de alertá-la acerca desse problema no Brasil e no mundo. 0 mês foi escolhido para a campanha porque 10 de setembro é o Dia Mundial de Prevenção ao Suicídio. O Outubro Rosa iniciou-se nos Estados Unidos desde o ano de 1997, objetivando a conscientização das mulheres sobre a importância da prevenção e do diagnóstico precoce do câncer de mama. 0 dia 19 de outubro é o Dia Mundial de Combate ao Câncer de Mama, por isso a campanha se realiza nesse mês. 0 movimento Novembro Azul iniciou-se em 2003, buscando conscientizar os homens a combaterem o câncer de próstata. A escolha desse mês para o foco na campanha se deve ao fato de o dia $17 \mathrm{de}$ novembro ser o Dia Mundial de Combate ao Câncer de Próstata.

A escolha do tema e do corpus se justifica pela importância da biopolítica e do seu propósito em todas as ações de "fazer viver", como também pela relevância do objetivo das campanhas em análise, as quais valorizam a vida e a saúde do público ao qual se dirigem.

Metodologicamente, esta pesquisa é caracterizada como descritivointerpretativa, uma vez que tanto se descreve quanto se interpreta os fatos observados. A abordagem é qualitativa, visto que fenômenos são interpretados e significados atribuídos (PRODANOV; FREITAS, 2013).

Após esta introdução, apresentamos uma breve discussão sobre o biopoder e a biopolítica. Na seção seguinte, trazemos a análise das estratégias biopolíticas nas materialidades discursivas selecionadas e por fim, tecemos as considerações finais.

\title{
Breves reflexões sobre o Biopoder e a Biopolítica
}

Aproximadamente em meados do século XIII, surge uma nova tecnologia de poder. "Agora é sobre a vida e ao longo de todo o seu desenrolar que o poder estabelece seus pontos de fixação" (FOUCAULT, 1988, p. 129). Essa tecnologia se opôs à teoria clássica da soberania, na qual o soberano "pode fazer morrer e deixar viver [...]" (FOUCAULT, 2005, p. 286) e da tecnologia disciplinar do trabalho, a qual "era centrada no corpo individual" (FOUCAULT, 2005, p. 288). 0 biopoder

\begin{abstract}
centrou-se no corpo-espécie, no corpo transpassado pela mecânica do ser vivo e como suporte dos processos biológicos: a proliferação, os nascimentos e a mortalidade, o nível de saúde, a duração da vida, a longevidade, com todas as condições que podem fazê-los variar; tais processos são assumidos mediante toda uma série de intervenções e controles reguladores: uma biopolítica da população. (FOUCAULT, 1988, p. 130, grifo do autor).
\end{abstract}

Assim, enquanto na teoria clássica da soberania o súdito só tinha o direito de vida e de morte pela vontade do soberano e na tecnologia disciplinar do trabalho o corpo era tido sob vigilância, inspeção, disciplina, o biopoder busca prolongar a vida da espécie humana e não discipliná-la, mas regulamentá-la (FOUCAULT, 2005). 0 poder disciplinar controla o corpo individualizado, já o 
biopoder controla o corpo coletivo, ou seja, em ambos os poderes há controle sobre o corpo.

A biopolítica atua a partir dos propósitos do biopoder, intervindo e controlando o que se refere à vida da população. Foucault afirma que a biopolítica trata

de um conjunto de processos como a proporção dos nascimentos e dos óbitos, a taxa de reprodução, a fecundidade de uma população, etc. São esses processos de natalidade, de mortalidade, de longevidade que, justamente na segunda metade do século XVIII, [...], constituíram, acho eu, os primeiros objetos de saber e os primeiros alvos de controle dessa biopolítica. (FOUCAULT, 2005, p. 290).

Isso significa que a vida, sua duração e também a morte são interesses das biopolíticas. A doença também é um alvo de controle das biopolíticas, "[...] a doença como fenômeno de população: não mais como a morte que se abate brutalmente sobre a vida - é a epidemia - mas como a morte permanente, que se introduz sorrateiramente na vida, a corrói perpetuamente, a diminui e a enfraquece." (FOUCAULT, 2005, p. 291). Assim, não só as epidemias são de preocupação da biopolítica, mas as doenças no geral. Logo, campanhas de combate a doenças que podem levar o sujeito a pensar em suicídio, campanhas de combate ao câncer de mama e de próstata, como as que são analisadas no presente trabalho, enlaçam-se a ações biopolíticas. Foucault ainda afirma:

Doenças mais ou menos difíceis de extirpar, e que não são encaradas como as epidemias, a título de causas de morte mais frequente, mas como fatores permanentes - e é assim que as tratam - de subtração das forças, diminuição do tempo de trabalho, baixa de energias, custos econômicos, tanto por causa da produção não realizada quanto dos tratamentos que podem custar. (FOUCAULT, 2005, p. 290).

A partir dessa afirmação de Foucault, convém observar que uma pessoa acometida por alguma doença não terá capacidade de trabalhar, devido às condições físicas e/ou psicológicas, o que vai gerar um custo tanto para a instituição na qual trabalha quanto para o Estado, pela necessidade do tratamento.

Então, o que põe em perigo a vida do ser humano, o que lhe tira a energia, a disposição, a capacidade de realizar algo, a consciência, a vitalidade de um modo geral são interesses da biopolítica. A biopolítica "faz viver e deixa morrer" (FOUCAULT, 2005), atua na preservação da vida e na qualidade de sua duração. Embora a biopolítica não seja efetivada a partir de técnicas disciplinares, tais como as empregadas em escolas, quartéis e hospitais, o biopoder e as biopolíticas não suplantam completamente essa tecnologia de poder, mas a sofistica, com vistas a governar a população. "Disciplinas e biopolítica se articulam, mas são distintas, diferentes são seus procedimentos", conforme destaca Calomeni $(2018$, p. 228, grifos da autora). 
O Estado assume esse papel de "fazer viver e deixar morrer", assumindo" assim o poder sobre a vida que "se instala por meio da instituição de diversos dispositivos de caráter sexual, pedagógico, clínico e penal, permitindo a capilarização das possibilidades de intervenção do Estado sobre a vida da população." (ASSMANN; PICH; GOMES; VAZ, 2007, p. 2). Nessa direção, é válido mencionar a questão da governamentalidade, da arte de governar.

Sobre a governamentalidade, consoante a ótica foucaltiana, com base em La Mothe Le Vayer, existem três tipos de governo: "o governo de si mesmo, que diz respeito à moral; a arte de governar adequadamente uma família, que diz respeito à economia; a ciência de bem governar o Estado, que diz respeito à política", (FOUCAULT, 1993, p. 278), o que significa que governar não é tarefa apenas do Estado, inclusive, Foucault (1993) cita que quem quiser governar o Estado, deve antes saber governar a si mesmo.

Foucault (1993) afirma ainda, de acordo com texto de La Perriére, que se governa a partir da relação entre homens e coisas, como acidentes, fome, epidemias, morte, entre outras, que, nesse caso, devem ser preocupações do Estado. Nesse sentido, em relação ao governo da população, biopoliticamente falando, conforme Foucault (1993) o objetivo deve ser melhorar a duração de vida, a saúde, etc., através de campanhas e técnicas.

Desse modo, além do Estado, a instituição privada também assume poder sobre a vida. Logo, postos de saúde, hospitais, escolas, universidades, ONG'S, entre outras instituições, públicas ou privadas, podem promover ações biopolíticas. "A atuação de mecanismos biopolíticos, nos dias de hoje, encontra-se pulverizada em diversos setores da sociedade", segundo Silva e Barbosa (2016, p. 88). Nesse contexto, é válido estabelecer uma relação com a afirmação de Deleuze (1992), de que com o advento da sociedade de controle, o poder é assumido de outras formas, não há mais um "limite" entre o público e o privado, a fábrica foi substituída por empresas que disputam o mercado capitalista dispersivo na venda de serviços e na compra de ações, através do marketing.

o "fazer viver", seja através da prevenção ou do tratamento de alguma doença é uma ação biopolítica, na qual "a vida situa-se como o objeto privilegiado de investimento e de apropriação do Estado moderno, o poder sobre a vida que torna a política bio-política." (ASSMANN; PICH; GOMES; VAZ, 2007, p. 5, grifos dos autores). Assim, "[...] as biopolíticas instauram comportamentos, regulam práticas e discursos, normatizam ações e atitudes, produzem subjetividades, no intuito de ensejar, especialmente, um bem-estar duradouro." (SILVA; BARBOSA, 2016, p. 91). Vê-se, então, a dimensão da atuação da biopolítica. De acordo com Sousa e Baracuhy,

com o surgimento da biopolítica, o homem se torna objeto do poder, integrando os fenômenos próprios à vida humana ao campo das técnicas políticas. Com isso, proliferaram tecnologias que investem sobre o corpo, a saúde, as maneiras de se alimentar e de morar, as condições de vida, etc. (SOUSA; BARACUHY, 2015, p. 135).

Portanto, a ação biopolítica reside no que diz respeito à vida, à saúde do ser humano, à sua alimentação, às condições de moradia, ao bem-estar, no geral, da população, entre outros aspectos relacionados ao "fazer viver e deixar morrer". Na 
próxima seção, discutiremos sobre as campanhas a partir das quais selecionamos as materialidades em análise neste trabalho.

\section{Análise das estratégias biopolíticas das campanhas selecionadas}

Nesta seção, trazemos a realização da análise. Segue a campanha do Setembro Amarelo:

Figura 1 - Campanha Setembro Amarelo

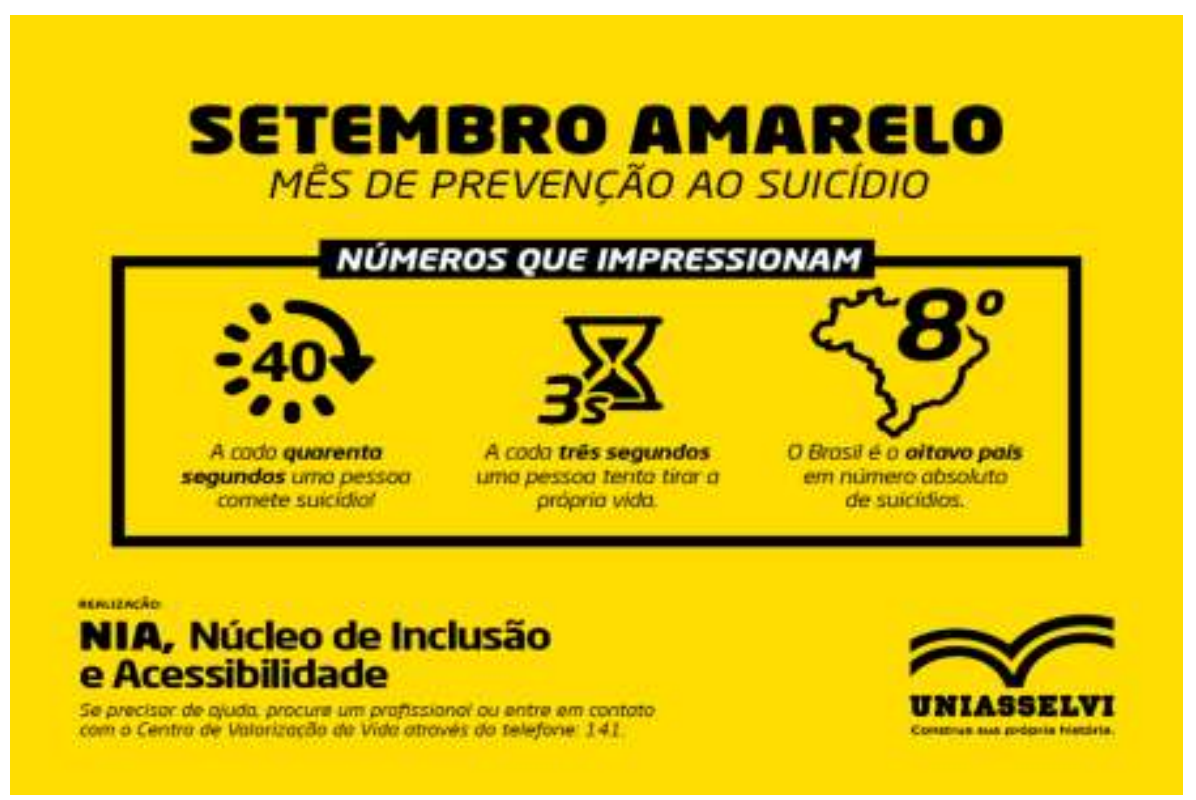
$\underline{\text { amarelo }}$

Fonte: https://portal.uniasselvi.com.br/noticias/geral/prevencao-ao-suicidio-acao-do-setembro-

Na Campanha Setembro Amarelo (Figura 1), de iniciativa do Núcleo de Inclusão e Acessibilidade da Uniasselvi, o discurso de conscientização acerca da prevenção ao suicídio se dá através de informações sobre o grande número de suicídios que ocorrem. A primeira informação é que alguém comete suicídio a cada 40 segundos e a cada 3 segundos alguém tenta se matar, além disso, o Brasil está na oitava posição em número de suicídios. A campanha ainda orienta a procura de um profissional para quem precisar de ajuda e informa o número do telefone do Centro de Valorização da Vida para contato.

Nessa campanha, há a presença de números que impressionam por indicarem a grande quantidade de pessoas que cometem suicídio. A biopolítica atua com base em dados, ou seja, "nos mecanismos implantados pela biopolítica, vai se tratar sobretudo, é claro, de previsões, de estimativas estatísticas, de medições globais; [...]. Vai ser preciso modificar, baixar a morbidade, vai ser preciso encompridar a vida; [...]" (FOUCAULT, 2005, p. 293). Isso significa que conforme previsões, dados estatísticos, medições, a biopolítica é aplicada na busca pela manutenção da vida. 
Vale ressaltar nossa compreensão de que essa campanha parece mais voltada ao público não potencialmente suicida, se considerarmos que a divulgação dos números deve impressionar os sujeitos que não têm tendência suicida para que ajudem o grupo potencialmente suicida, fiquem atentos a suas atitudes a fim de evitar, de algum modo, o suicídio. Não se pode desconsiderar, inclusive, que a divulgação de dados referentes a suicídios pode acabar estimulando o ato naqueles com fortes tendências suicidas, o que pode causar efeito contrário ao que objetiva a Campanha do Setembro Amarelo. Por ser o suicídio um assunto muito delicado, não se pode descartar equívocos ou contradições emergentes da circulação de campanhas desse tipo.

Por outro lado, a mensagem "se precisar de ajuda, procure um profissional ou entre em contato com o Centro de Valorização da Vida através do telefone: 141", direciona-se aos sujeitos que podem estar pensando, ou tentando suicídio, orientando-os a buscar ajuda.

Assim, vê-se que a estratégia biopolítica dessa campanha do Setembro Amarelo está na busca de alertar os que não são potenciais suicidas para a gravidade do número de suicídios, que precisa ser combatido, e na indicação, para o suicida em potencial, de uma instituição, o Centro de Valorização da Vida, que pode ajudar, assim como um profissional. Logo, a lógica biopolítica da campanha em questão volta-se para conscientizar tanto os sujeitos que pensam ou tentam se suicidar, quanto os demais, mostrando que todos devem combater o suicídio, valorizar e preservar a vida.

O suicídio, definido por Durkheim como "todo caso de morte que resulta direta ou indiretamente de um ato, positivo ou negativo, realizado pela própria vítima e que ela sabia que produziria esse resultado" (DURKHEIM, 2000, p. 14) era considerado crime na vigência da teoria clássica da soberania, "pois era um modo de usurpar o direito de morte que somente os soberanos, o daqui debaixo ou o do além, tinham o direito de exercer." (FOUCAULT, 1988, p. 129). Outrossim, o suicídio contraria a lógica da biopolítica, uma vez que enquanto a biopolítica "faz viver", valoriza e preserva a vida, o suicídio é um ato de ceifar a vida, de buscar a morte.

Abaixo, temos a campanha do Outubro Rosa.

Figura 2 - Campanha Outubro Rosa 


\section{PREVENIR O CÂNCER DE MAMA DEPENDE (MUITO) DE VOCÊ}
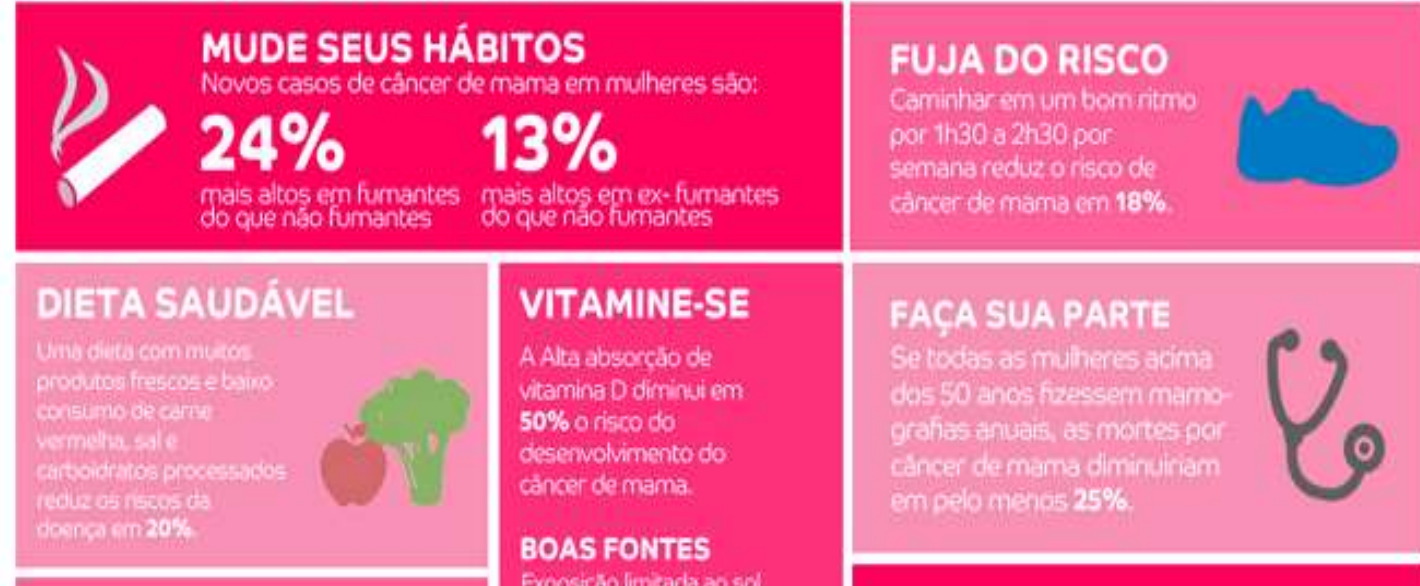

VITAMINE-SE

A Alla absorcdo de

Vitamina Q dimini em

$50 \%$ oriscodo

desenvolvimento do

cancer de mama

BOAS FONTES

Expositso limizada ao sol

MULHERES DE FIBRA

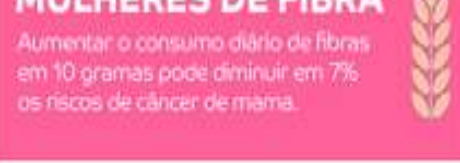

Salmbo

Acum
Lete foriticado

cereal forthicado
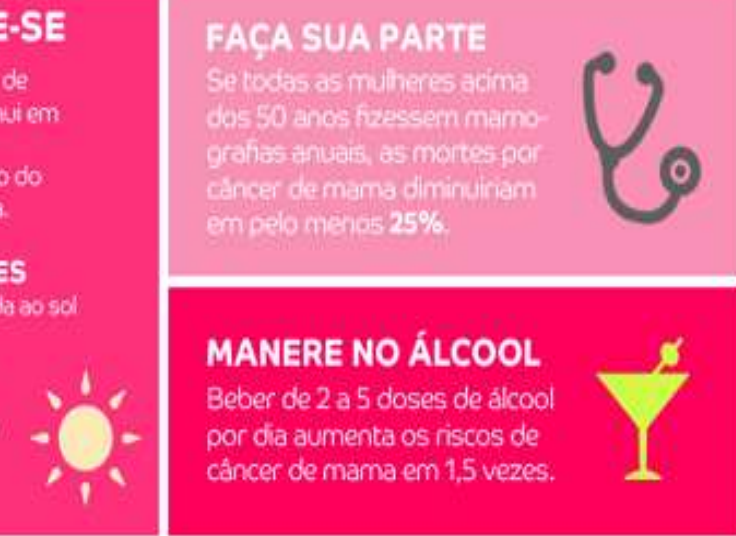

MANERE NO ÁLCOOL

Beber de 2 a 5 doses de álcool

por dia aumenta os riscos de

cáncer de mama em 1,5 vezes.

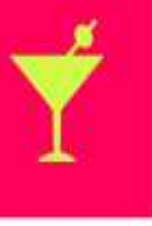

DE OLHO NA BALANÇA

Muiheres que ganham mais de 27 quilos depois dos

18 anos dobram as chances de desenvolverem

cancer de mama depois da menopausa.

Intográfico desenvolvido pela NorthShore

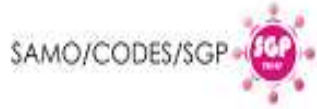

Fonte: https://www.blogderocha.com.br/campanha-outubro-rosa-tre-ap-orienta-servidorassobre-prevencao-ao-cancer-de-mama/outubro-rosa-2/

A campanha realizada pelo SGP, Sistema de Gerenciamento de Programas do Ministério da Saúde, apresenta o uso do imperativo, como uma maneira de guiar a conduta das mulheres. Mais uma vez, observa-se a presença de dados, os quais assinalam um efeito de verdade.

O infográfico traz um discurso de orientação para que as mulheres possam se prevenir do câncer de mama deixando de fumar e/ou não criando o hábito de fumar, uma vez que os casos de câncer de mama são mais altos em fumantes e em ex-fumantes; caminhando cerca de $1 \mathrm{~h} 30$ a 2h30 por semana, já que esse hábito diminui os riscos de se adquirir a doença. Além disso, o infográfico orienta o aumento do consumo de produtos frescos e a diminuição do consumo de carne vermelha, sal e carboidratos processados, também para que o risco de ter a doença seja diminuído e orienta a absorção de vitamina $\mathrm{D}$ através de exposição ao sol, mas sem exageros, através do consumo de salmão, atum, leite e cereal fortificados, porque a taxa alta da vitamina $\mathrm{D}$ também reduz as chances de aquisição do câncer de mama. No caso das mulheres com idade superior a 50 anos, devem fazer mamografia anualmente, também aumentar o consumo de fibras, evitar álcool e ficar atentas ao peso são hábitos que evitam a doença. 
Fica claro, portanto, que a biopolítica nessa campanha busca atingir o objetivo de preservar a vida das mulheres e prevenir o câncer de mama através da conscientização do público feminino em relação ao controle da alimentação e à prática de caminhada, enfatizando, assim, que a prevenção do câncer depende muito da mulher, a qual deve criar certos hábitos e abandonar outros como modo de se prevenir e afastar os riscos de ser acometida pelo câncer de mama. Nesse sentido, acerca da governamentalidade de si, conforme Sousa e Baracuhy,

o sujeito também deve governar a si, por meio do controle de suas práticas, seus hábitos, porque eles envolvem não só sua vida, mas a vida de toda a população. Se há muitos indivíduos morrendo, é sinal que o governo não está cuidando de seus governados e nem conseguindo fazê-los cuidar de si mesmos. (SOUSA; BARACUHY, 2015, p. 137).

Logo, a preservação da vida não é "dever" apenas das biopolíticas, através do Estado ou de outras instituições, por exemplo. É dever de cada ser humano cuidar de si e preservar sua vida, controlando práticas e hábitos, evitando doenças e buscando bem-estar.

Essa campanha volta-se, então, para a gestão da saúde alimentar objetivando a segurança das mulheres a fim de que, através da alimentação saudável, evite-se o desenvolvimento do câncer de mama. Essa ação, consequentemente, "reduzirá, por parte do governo, os custos com saúde pública." (SILVA, 2018, p. 243).

Vale ressaltar que a biopolítica relaciona-se não só à vida, mas também à morte. Com base nas estatísticas de casos de morte por câncer de mama, buscamse meios de evitar a morte, e a prevenção é o principal meio, tendo assim um caráter biopolítico. Logo para agir sobre a vida, não se pode desconsiderar a morte.

Segue a campanha do Novembro Azul:

Figura 3 - Campanha Novembro Azul

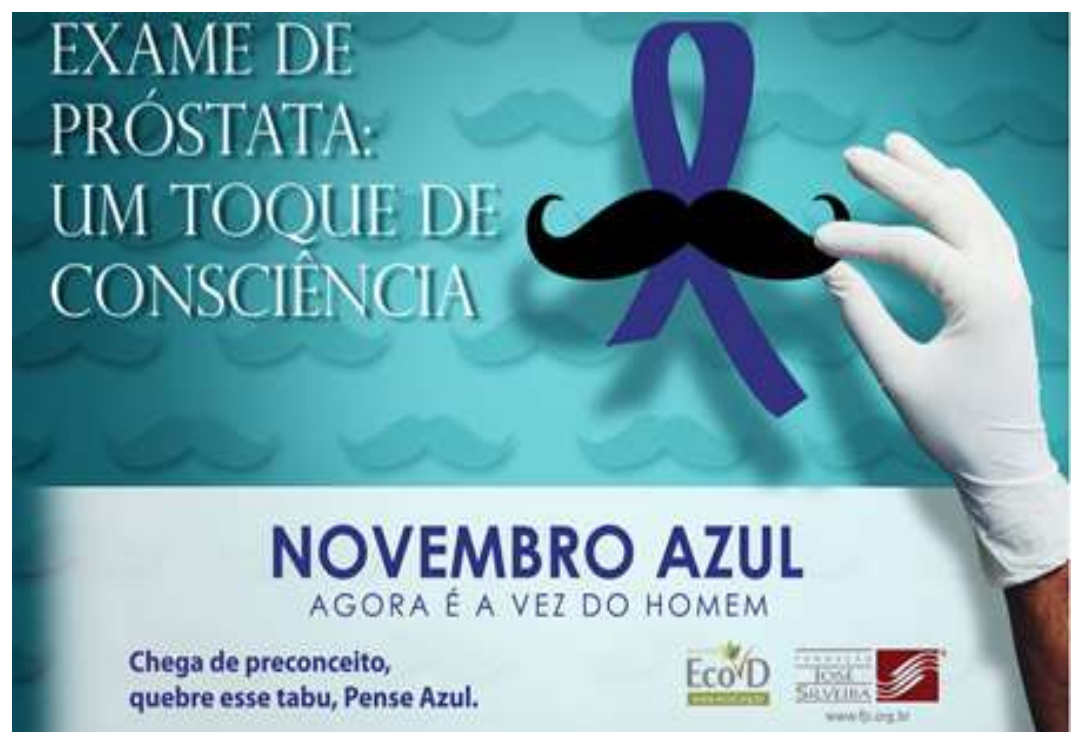


Fonte: http://www.ecodesenvolvimento.org/posts/2014/hoje-e-o-dia-mundial-decombate-ao-cancer-de

$\mathrm{Na}$ Campanha do Novembro Azul (Figura 3), promovida pela Eco Desenvolvimento e pela Fundação José Silveira, utiliza-se um discurso buscando-se alertar os homens a fazerem o exame de próstata e a abandonarem o preconceito que muitos têm acerca desse exame. Tal preconceito existe pelo fato de o exame ser feito através do toque de um médico urologista no reto do paciente, de modo que muitos têm vergonha ou não aceitam ser tocados dessa forma por outro homem. Esse preconceito pode ser explicado por Foucault (1988), ao mostrar que, no final do século XVIII, houve controle sobre a sexualidade. "Romper as leis do casamento ou procurar prazeres estranhos mereciam de qualquer modo, condenação [...]. Quanto aos tribunais, podiam condenar tanto a homossexualidade quanto a infidelidade, o casamento sem consentimento dos pais ou a bestialidade." (FOUCAULT, 1988, p. 37-38). Dessa forma, a homossexualidade era condenada, assim como é, ainda hoje, por muitas pessoas, o que justifica a evitação de muitos homens de ao menos se aproximarem de outro. É válido considerar que esse preconceito quanto ao exame de toque acaba representando um obstáculo à ação biopolítica de evitar o câncer de próstata.

Vale ressaltar que na campanha em análise há uma ressignificação do termo "toque" na expressão "toque de consciência", aludindo à rejeição dos homens em se submeterem ao exame e incentivando a serem conscientes quanto à necessidade de realização desse procedimento.

Logo, nessa campanha, o propósito biopolítico de preservar a vida dos homens, principalmente dos mais velhos, está no estímulo ao exame como uma questão de consciência e na quebra de um tabu, já que o preconceito com o toque faz muitos evitarem o procedimento, aumentando, assim, o risco de aquisição do câncer de próstata pela falta de prevenção. Além disso, o discurso "Agora é a vez do homem", remete à ideia de que a mulher já teve sua vez de ser alertada quanto à prevenção, e a expressão "Pense Azul" convida o público masculino a aderir à campanha e a prevenir-se, conforme objetiva o Novembro Azul, "movimento que tem como antípoda o Outubro Rosa, para conscientizar a população masculina em relação à necessidade de realizar exames preventivos, com vistas a tratar o câncer de próstata." (SILVA; LEITE, 2014, p. 88)

Assim, "a urgência em cuidar da saúde e manter uma vida saudável constitui-se numa exigência peculiar no momento presente." (SILVA; LEITE, 2014, p. 89). Nessa direção, é crucial que o público masculino desprenda-se de preconceitos relacionados ao exame de próstata e se conscientize sobre a necessidade da prevenção.

Vale reiterar que a biopolítica se preocupa com a vida e com o que a ameaça, preocupando-se também com a doença. Desse modo, como uma forma de impedir que a doença ameace a vida, as campanhas de prevenção caracterizam-se como estratégias biopolíticas. Assim, o cunho biopolítico dessa campanha do Novembro Azul, como também das campanhas do Setembro Amarelo e do Outubro Rosa, coadunam com o que afirma Nespoli sobre a atuação da biopolítica: 
[...], a biopolítica opera um controle sobre os fenômenos coletivos e vai trabalhar, sobretudo, na produção de uma população saudável e utilizar estratégias e mecanismos regulamentadores que buscarão, de várias maneiras, fixar um equilíbrio, alcançar uma média e otimizar um estado de vida. (NESPOLI, 2014, p. $65)$.

Considerando-se que a doença, o câncer de mama, o de próstata ou qualquer outra, assim como a morte, configura-se como um fenômeno coletivo, que atinge inúmeras pessoas da sociedade, a biopolítica trabalha pela saúde da população, por meio de uma regulamentação que tanto otimize a vida, quanto a preserve, evitando a doença e, consequentemente, também evitando e postergando a morte.

\section{Considerações finais}

Das discussões, pudemos apreender como atua a biopolítica, seus campos de interesse e seu propósito, principalmente, da proteção da vida. Ademais, foi possível ampliar o conhecimento acerca do Setembro Amarelo, do Outubro Rosa e do Novembro Azul e relacionar os objetivos dessas campanhas às estratégias biopolíticas.

A partir das materialidades discursivas que selecionamos para proceder com a realização da análise, constatamos, portanto, as estratégias biopolíticas presentes nos discursos de conscientização, de sensibilização e de alerta em relação aos dados relativos a suicídio, aos riscos do câncer de mama e do câncer de próstata.

A campanha do Setembro Amarelo chama a atenção para o grande número de suicídios em escala mundial, colocando o Brasil entre os dez países onde mais se pratica suicídio, buscando-se assim proteger a vida, mostrando-se a gravidade da situação. A campanha Outubro Rosa objetiva assegurar a saúde e prevenir o câncer de mama por meio de orientações para uma alimentação saudável e prática de exercício físico. Já a campanha Novembro Azul alerta para a necessidade de se abandonar o preconceito em relação ao exame de toque a fim de que o homem se previna do câncer de próstata.

Logo, as três campanhas analisadas apresentam o propósito biopolítico de preservar a vida, prevenir doenças e evitar a morte, bem como de assegurar a saúde, orientando mudanças de comportamento e de atitudes, sobretudo em relação à conscientização da importância e da necessidade da prevenção. Desse modo, percebemos que a biopolítica é um mecanismo de controle do corpo, da saúde e da vida desenvolvido não só pelo Estado, mas por instituições diversas, todas unidas pelo bem comum de "fazer viver e deixar morrer". 0 próprio ser humano deve ter também um propósito biopolítico em relação a sua vida, governando a si mesmo no sentido de cuidar-se através, por exemplo, da procura por ajuda em casos de pensamentos suicidas, da adoção de hábitos como alimentação saudável e prática regular de exercícios físicos e da realização de exames preventivos. 


\section{Notas}

1 Disponível em: <https://portal.uniasselvi.com.br/noticias/geral/prevencao-ao-suicidio-acao-dosetembro-amarelo $>$. Acesso em: 20 dez. 2018.

2 Disponível em: <https://www.blogderocha.com.br/campanha-outubro-rosa-tre-ap-orientaservidoras-sobre-prevencao-ao-cancer-de-mama/outubro-rosa-2/>. Acesso em: 20 dez. 2018.

3 Disponível em: <http://www.ecodesenvolvimento.org/posts/2014/hoje-e-o-dia-mundial-decombate-ao-cancer-de>. Acesso em: 20 dez. 2018.

\section{Referências}

ASSMANN, S.; PICH, S; GOMES, I. M.; VAZ, A. F. Corpo e Biopolítica: poder sobre a vida e poder da vida. In: XV Congresso Brasileiro de Ciências do Esporte e II Congresso Internacional de Ciências do Esporte, 2007, Pernambuco. Anais[...] Pernambuco, 2007. p. 1-9. Disponível em: http://www.cbce.org.br/docs/cd/resumos/119.pdf. Acesso em: 20 dez. 2018.

CALOMENI, T. O ronco surdo da batalha: poder disciplinar e biopolítica. In: RESENDE, H. (Org.). Michel Foucault: o ronco surdo da batalha. São Paulo: Intermeios, 2018, p. 215-239.

DELEUZE, G. Post-Scriptum sobre as sociedades de controle. In: DELEUZE, G. Conversações (1972 - 1990). Tradução de Peter Pál Pelbart. Rio de Janeiro: Editora 34, 1992, p. 219-226.

DURKHEIM É. O Suicídio: estudo de sociologia. Tradução de Mônica Stahel. São Paulo: Martins Fontes, 2000.

ECO DESENVOLVIMENTO; FUNDAÇÃO JOSÉ SILVEIRA. Exame de próstata: um toque de consciência. Disponível em: http://www.ecodesenvolvimento.org/posts/2014/hoje-e-odia-mundial-de-combate-ao-cancer-de. Acesso em: 14 dez. 2018.

FOUCAULT, Michel. História da Sexualidade I: A vontade de saber. Tradução de Maria Thereza da Costa Albuquerque e J. A. Guilhon Albuquerque. 13. ed. Rio de Janeiro: Edições Graal, 1988.

FOUCAULT, Michel. Microfísica do Poder. 11. ed. Rio de Janeiro: Graal, 1993.

FOUCAULT, M. Aula de 17 de março de 1976. In: FOCAULT, M. Em Defesa da Sociedade. Curso no Collège de France (1975-1976). Tradução de Maria Ermantina Galvão. São Paulo: Martins Fontes, 2005.

NESPOLI, G. Biopolíticas da participação na saúde: o SUS e o governo das populações. In: GUIZARDI, F. L. et al (Org.). Políticas de participação e saúde. Rio de Janeiro: EPSJV; Recife: Editora Universitária UFPE, 2014. p. 59-90.

NOVEMBRO AZUL: A IMPORTÂNCIA DE SE CUIDAR. Disponível em: https://www.cancer.org.br/novembro-azul-a-importancia-de-se-cuidar/. Acesso em: 20 dez. 2018. 
NÚCLEO DE INCLUSÃO E ACESSIBILIDADE, UNIASSELVI. Setembro Amarelo: mês de prevenção do suicídio, números que impressionam. Disponível em:

https://portal.uniasselvi.com.br/noticias/geral/prevencao-ao-suicidio-acao-dosetembro-amarelo. Acesso em: 14 dez. 2018.

O SUICÍDIO. Disponível em: http://www.setembroamarelo.org.br/o-suicidio/. Acesso em: 20 dez. 2018.

OUTUBRO ROSA. Disponível em: https://www.cancer.org.br/sobre-o-cancer/eventos-ecampanhas/nossas-campanhas/outubro-rosa/. Acesso em: 20 dez. 2018.

PRODANOV, C. C; FREITAS, E. C. de. Metodologia do trabalho científico [recurso eletrônico]: métodos e técnicas da pesquisa e do trabalho acadêmico. 2. ed. Novo Hamburgo: Feevale, 2013. Disponível em: http://www.feevale.br/Comum/midias/8807f05a-14d0-4d5bb1ad-1538f3aef538/E-book\%20Metodologia\%20do\%20Trabalho\%20Cientifico.pdf. Acesso em: 13 dez. 2018.

SILVA, F. V. Muito além do peso: modulações biopolíticas em discursos sobre a obesidade infantil. Calisdoscópio, Unisinos, v. 16, n. 2, p. 237-248, mai/ago, 2018.

SILVA, F. V; BARBOSA, M. do S. F. Humaniza redes: uma questão biopolítica. Acta Scientiarum. Human and Social Sciences, Maringá, v. 38, n. 1, p. 85-92, jan/jun 2016. Disponível em: <http://periodicos.uem.br/ojs/index.php/ActaSciHumanSocSci/article/view/28321>. Acesso em: 20 dez. 2018.

SILVA, F. V; LEITE, F. F. A testosterona \& a vida: a emergência dos discursos sobre a saúde do homem na mídia. Revista Língua \& Literatura, v. 16, n. 27, p. 71-93, dez 2014. Disponível em: http://revistas.fw.uri.br/index.php/revistalinguaeliteratura/article/view/1528/1832. Acesso em: 22 abr. 2019.

SISTEMA DE GERENCIAMENTO DE PROGRAMAS, MINISTÉRIO DA SAÚDE. Prevenir o câncer de mama depende (muito) de você. Disponível em:

$<$ https://www.blogderocha.com.br/campanha-outubro-rosa-tre-ap-orienta-servidorassobre-prevencao-ao-cancer-de-mama/outubro-rosa-2/>. Acesso em: 14 dez. 2018.

SOUSA, C; BARACUHY, R. Biopolítica, biopoder e cuidado de si na campanha antitabagista das embalagens de cigarro. Ilha do Desterro: A Journal of English Language, Literatures in English and Cultural Studies, Florianópolis, Brasil, v. 68, n. 3, p. 131-146, set/dez 2015. Disponível em: $<$ https://periodicos.ufsc.br/index.php/desterro/article/view/21758026.2015v68n3p131>. Acesso em: 20 dez. 2018.

\section{Para citar este artigo}

BEZERRA, Jaqueline de Jesus; SILVA, Francisco Vieira da. As cores da vida: estratégias biopolíticas nas campanhas setembro amarelo, outubro rosa e novembro azul. Miguilim Revista Eletrônica do Netlli, Crato, v. 8, n. 2, p. 728-741, maio-ago. 2019. 
Jaqueline de Jesus Bezerra é Mestra em Letras pela Universidade Federal de Campina Grande (UFCG) e doutoranda do Programa de Pós-Graduação em Letras (PPGL) na Universidade do Estado do Rio Grande do Norte (UERN).

Francisco Vieira da Silva é Doutor em Linguística pela Universidade Federal da Paraíba (UFPB). Professor Adjunto da Universidade Rural do Semi-Árido (UFERSA) e do Programa de Pós-Graduação em Letras (PPGL) da Universidade do Estado do Rio Grande do Norte (UERN). 